\title{
Calls of North Atlantic right whales Eubalaena glacialis contain information on individual identity and age class
}

\author{
Jessica A. McCordic ${ }^{*}$, Holly Root-Gutteridge, Dana A. Cusano, Samuel L. Denes, \\ Susan E. Parks
}

Department of Biology, Syracuse University, Syracuse, NY 13244, USA

\begin{abstract}
Passive acoustic monitoring is a powerful tool that allows remote detection of marine mammals through their vocalizations. While call detection provides information on species presence, additional information may be contained within the vocalizations that could provide more information regarding the demographics and/or number of individuals in a particular area based on passive acoustic detections. The North Atlantic right whale Eubalaena glacialis produces a stereotyped upswept call, termed the upcall, that is thought to function as a long-distance contact call in this species. As such, the call is likely to contain cues providing information about the individual producing it. The goal of this study was to test whether the right whale upcall could potentially encode information related to the identity and age of the caller. Using upcalls recorded from 14 known individuals through non-invasive suction cup archival acoustic tags, we demonstrate that the upcall does contain sufficient information to discriminate individual identity and age class, with average classification levels of 72.6 and $86.1 \%$, respectively. Parameters measured from the fundamental frequency, duration, and formant structure were most important for discrimination among individuals. This study is the first step in demonstrating the feasibility of obtaining additional data from passive acoustic monitoring to aid in the conservation efforts for this highly endangered species.
\end{abstract}

KEY WORDS: Right whale - Acoustic communication - Vocal signature · Individual recognition * Passive acoustic monitoring $\cdot$ Formants

\section{INTRODUCTION}

The North Atlantic right whale Eubalaena glacialis is one of the most closely studied mysticete whales in the world (Kraus et al. 2005). Due to its endangered status and slow population recovery rate (Caswell et al. 1999), there has been great interest in tracking the population and distribution of these whales within their coastal habitats to assist in the implementation of suitable management strategies that minimize the risk of vessel collisions or entanglement in fishing gear (Kraus et al. 2005).

Several methods have been used to monitor this species, including traditional visual vessel and aerial

${ }^{*}$ Corresponding author: jamccord@syr.edu surveys as well as marine passive acoustic monitoring (PAM) (Brown et al. 2007, Van Parijs et al. 2009). PAM utilizes recorded acoustic data from either manned recorders, such as a hydrophone towed behind a vessel, or unmanned, autonomous recorders (Zimmer 2011, Sousa-Lima et al. 2013). From a methodological standpoint, autonomous recorders are particularly useful in the marine environment as they allow continuous, long-term monitoring regardless of light or weather conditions (Mellinger et al. 2007b, Au \& Hastings 2010). PAM can be used to detect vocalizations and provide insight into seasonal habitat use and movement patterns, making it an excellent tool for remote monitoring of vocal endan-

() The authors 2016. Open Access under Creative Commons by Attribution Licence. Use, distribution and reproduction are unrestricted. Authors and original publication must be credited. 
gered species (Mellinger et al. 2007b, Van Parijs et al. 2009). There is growing interest in the use of PAM for greater insight into population ecology, including inferring behavioral activities based on sound types and obtaining robust estimates of the density of individuals in a given location in both terrestrial and marine habitats (Blumstein et al. 2011, Marques et al. 2013). Multiple sensors may be used to localize and track calling individuals, providing an estimate of the number of calling animals (Van Parijs et al. 2009, Stanistreet et al. 2013). Density estimation is also possible from single sensors via a cue counting approach using known call rates (Dawson \& Efford 2009, Küsel et al. 2011, Marques et al. 2011). If the recorded vocalizations also contain measurable differences among individuals, these differences can improve density estimation, providing information on the minimum number of calling individuals and adding to estimates obtained from cue counting or other methods (Terry et al. 2005).

Individually distinctive acoustic signals are common across vertebrate taxa (Reby et al. 1998, Bee et al. 2001, Christie et al. 2004, Clemins et al. 2005, Gillam \& Chaverri 2012). Studies of individual distinctiveness often focus on vocalizations produced within specific contexts in which the receiver is likely to benefit from being able to discriminate among individuals, such as alarm calls (Blumstein \& Munos 2005), reproductive calls (Vannoni \& McElligott 2007), or parent-offspring calls (Charrier et al. 2009). Signal individuality, however, can occur without requiring receiver discrimination (Tibbetts \& Dale 2007). In mammals, individual differences in the physical traits of the vocal production anatomy contribute to corresponding variations in the calls. These differences can be evaluated by targeting particular acoustic measurements, including the fundamental frequency and formants - broad spectral peaks resulting from the filtering effect of the vocal tract (Titze 2000). Throughout this article, we use the term 'formant' to refer to the broad spectral peaks that result in emphasis of the amplitudes of subsets of harmonics of the fundamental frequency of a call. When characterizing differences among individuals producing the same call types, a combination of fundamental frequency and formant measurements is especially useful (Reby et al. 1998, 2005, Bachorowski \& Owren 1999, Vannoni \& McElligott 2007, Charlton et al. 2009, Taylor \& Reby 2010). Following research into human speaker recognition (Kinnunen \& Li 2010), multiple classification methods have been developed to use these measurements of acoustic features to discriminate among individuals: hidden
Markov models (e.g. Reby et al. 2006, Nichols et al. 2010), neural networks (e.g. Peake \& McGregor 2001, Terry \& McGregor 2002), and most frequently, discriminant function analysis (DFA) (e.g. Gillam \& Chaverri 2012, Cinková \& Policht 2014, Mumm et al. 2014).

Within marine mammals, individuality has been demonstrated in both pinniped and cetacean vocal behavior. This applies to all pinniped species that have been tested (Insley et al. 2003): sub-Antarctic fur seals Arctocephalus tropicalis (Charrier \& Harcourt 2006), Australian sea lions Neophoca cinerea (Gwilliam et al. 2008), Weddell seals Leptonychotes weddellii (Van Opzeeland et al. 2012) and several cetacean species including humpback whales Megaptera novaeangliae (Hafner et al. 1979), killer whales Orcinus orca (Nousek et al. 2006, Nichols et al. 2010, Kremers et al. 2012), sperm whales Physeter macrocephalus (Antunes et al. 2011), and bottlenose dolphins Tursiops truncatus (Caldwell \& Caldwell 1965, Sayigh et al. 2007). Signature whistles of bottlenose dolphins are perhaps the most well-known of these examples, partially due to the dramatic differences in fundamental frequency contours among individuals (Janik \& Sayigh 2013). Typically, however, acoustic differences among individuals are much more subtle and require several acoustic measurements to achieve statistical discrimination. Despite the precedent for vocal individuality within marine mammals, to our knowledge there has only been a single published quantitative assessment of individual distinctiveness in calls of any mysticete whale: an analysis conducted using songs of humpback whales recorded from adult males (Hafner et al. 1979).

North Atlantic right whales produce a variety of sounds, which have been extensively studied (Matthews et al. 2001, Parks \& Tyack 2005, Parks et al. 2011). The upcall, originally described in southern right whales Eubalaena australis (Clark 1982), is a stereotyped call within the repertoire of North Atlantic right whales, produced by all age classes and both sexes, and thought to function as a long-distance contact call (Parks \& Clark 2007). This call is also the most commonly used in PAM studies to detect the presence of right whales in different habitat areas (e.g. Mellinger et al. 2007a, Van Parijs et al. 2009, Morano et al. 2012).

The goal of this study was to explore the potential for individual variation within the upcall of the North Atlantic right whale. We selected the upcall for 3 reasons. (1) It is thought to function as a long-range contact call (Clark 1982). (2) It is the predominant call 
type used in PAM of North Atlantic right whales (Mellinger et al. 2007a). (3) It is produced by all age classes and both sexes, allowing an assessment of the same call type across all individuals (Parks et al. 2011). Predictable variation in signal characteristics by individual or age class could provide additional insight into the ecology and aid in the management of this species.

\section{MATERIALS AND METHODS}

\section{Data collection}

\section{Acoustic tag recordings}

Data were collected from North Atlantic right whales using suction-cup-attached digital archival acoustic recording tags (DTAG: Johnson \& Tyack 2003; Acousonde: Burgess 2009) as part of other research efforts in 3 of the critical habitat areas for this species (Kraus \& Rolland 2007): the Bay of Fundy, Canada (Nowacek et al. 2001, 2004, Johnson \& Tyack 2003); Cape Cod Bay, Massachusetts, USA (Parks et al. 2011); and the Southeastern US (Nousek-McGregor 2010). Tags were equipped with a hydrophone, 3-axis accelerometer, magnetometer, and pressure sensors (Nowacek et al. 2001, Johnson \& Tyack 2003). Depending on the year of tagging and tag type, acoustic data were sampled between 16 and $96 \mathrm{kHz}$. For this study, all acoustic data were resampled to $16 \mathrm{kHz}$ using AviSoft SASLab Pro v.5.2 (Avisoft Bioacoustics) prior to analysis. After a period of behavioral observation and photo-identification to determine the identity of a whale, tags were deployed from small vessels using a carbon-fiber pole according to methods described in Nowacek et al. (2001, 2004).

\section{Individual identification of tagged whales}

Right whales have individually distinctive patterns of rough patches of skin called callosities on their rostrum, mandibles, and near their blowhole (Kraus et al. 1986). Photographs of tagged whales were compared to a catalog of identified right whales maintained by the North Atlantic Right Whale Consortium (Hamilton \& Martin 1999, Right Whale Consortium 2015). The catalog includes information about each whale's sex as determined using either visual assessment of the genital slit (Payne \& Dorsey 1983) or genetic information obtained via skin biopsy (Brown et al. 1994). Exact age was only known if a right whale was sighted with its mother during its first year, but a minimum age for all other whales can be estimated as the number of years elapsed since the first sighting of the animal (Right Whale Consortium 2015). The average age of first calving for female right whales is 9 yr (Payne \& Dorsey 1983, Kraus \& Hatch 2001); thus for this study, whales were assigned to 2 age classes: 'juvenile', if their age at time of tagging was known to be between 1 and $8 \mathrm{yr}$, and 'adult' if their exact age or minimum age at time of tagging was 9 yr or greater.

\section{Call selection and acoustic measurements}

Spectrograms of complete recordings from tags were visually and aurally inspected for the presence of upcalls using the sound analysis program Raven Pro v.1.5 (Cornell Bioacoustics Research Program). Following Parks et al. (2011), we only selected upcalls with a high signal-to-noise ratio (SNR) (i.e. $>10 \mathrm{~dB}$ ) produced when the tagged whales were observed to be alone during focal follows, providing a high confidence that the call was produced by the tagged whale.

\section{Formant measurements}

Without in situ observations of vocal physiology while vocalizing, there is no way to confirm that the spectral peaks seen in marine mammal vocalizations result from the same mechanisms as the formants of terrestrial mammals. However, there are structural homologies between the vocal anatomy of terrestrial mammals and mysticete whales (Reidenberg \& Laitman 2007), and the spectral structure of mysticete whale calls is consistent with observations of formants in terrestrial mammals (Mercado et al. 2010, Cazau et al. 2013). Harmonics are whole-number multiples of the fundamental frequency of a signal, and typically decrease in amplitude with increasing frequency. Vocal tract resonances and filtering can result in emphasis or de-emphasis of select frequency bands. Thus the frequency value of the peak energy of the formants is independent of the fundamental frequency.

We measured formants in upcalls using the open source speech analysis software Praat v.5.3.17 (Boersma \& Weenik 2012). Praat applies a Gaussianlike window and computes the linear predictive coefficients using Burg's algorithm (Boersma \& Weenik 
2012). Linear predictive coefficients represent data as a combination of the spectral characteristics and the excitation signals through the linear combination of neighboring data points (Makhoul 1975). To remove formants that are too low or high to be associated with vocal tract resonances, Praat further removes all measured formants below a set value of $50 \mathrm{~Hz}$ and above the maximum formant value minus $50 \mathrm{~Hz}$, here given as $5500 \mathrm{~Hz}$ (Boersma \& Weenik 2012). We used 0.25 s segments centered on the midpoint of the call to reduce the influence of background noise. In human speech analysis, similar segmentation is used to extract formant values from vowels while avoiding the influence of surrounding consonants (Rendall et al. 2005). The frequency values of the formants were automatically extracted from each $0.25 \mathrm{~s}$ clip using the 'Linear Predictive Coding (LPC): To Formant (Burg)' command within a custom Praat script. Analysis parameters were as follows: time step $=0.0$ (auto), maximum number of formants $=5$, maximum formant $=5500 \mathrm{~Hz}$, window length $=0.025 \mathrm{~s}$, pre-emphasis from $50 \mathrm{~Hz}$. Although only the first 3 formants were used in the analysis, the maximum formant value was set to 5 based on visual assessment of the formant tracking performance in Praat. When using a maximum formant value set to 3 , the highest frequency peak energy tracked by LPC did not correspond to the approximate formant structure of the call as visually assessed in the underlying spectrograms.
To address this concern, we set the maximum number of formants to 5 , forcing the LPC to extract 5 peaks between 50 and $5500 \mathrm{~Hz}$. We then retained the 3 formants that corresponded to the spectral content of the vocalization and excluded the 2 inconsistently tracked 'false' formants measured from spectral peaks in the noise in frequencies above the vocalization (i.e. no consistent formant structure across successive time-steps). Pre-emphasis lessens the overall effect of decreased energy at higher frequencies and allows the LPC analysis to treat all frequencies with equal weight. The mean formant frequency value for each of the first 3 formants across the entire segment was then used as the value of each formant for each call (Table 1). Examples of spectrograms where the formants are highlighted are shown in Fig. 1 for 2 individuals (juvenile male 3579 and adult female 1604).

\section{Time-frequency measurements}

Due to fluctuations in background noise, automated detection of the fundamental frequency in Praat resulted in errant contours with occasional rapid frequency jumps that did not reflect the actual vocalization being measured. Therefore, we developed a custom script for MATLAB (Release 2012a; Mathworks) that allowed manual adjustment of automatically extracted contours for subsequent measure-

Table 1. Measurement variables used to discriminate upcalls of North Atlantic right whales Eubalaena glacialis by individual and age class

Measurement

Description

Minimum fundamental frequency $(\mathrm{Hz})$

Maximum fundamental frequency $(\mathrm{Hz})$

Start fundamental frequency $(\mathrm{Hz})$

End fundamental frequency $(\mathrm{Hz})$

Mean fundamental frequency $(\mathrm{Hz})$

Coefficient of variation of fundamental

frequency $(\mathrm{Hz})$

Duration 95\% (s)

Inflection point (\%)

Formants $1-3(\mathrm{~Hz})$

Kurtosis of spectrum

Skewness of spectrum

Quartile harmonics (1-3)

Spectral entropy
Minimum value in frequency contour

Maximum value in frequency contour

First value in frequency contour

Last value in frequency contour

Mean value of frequency contour

The ratio of the standard deviation of the contour frequencies to the mean value of the contour (a measure of variability)

Difference between time points marking 97.5 and $2.5 \%$ of spectrogram power spectral density

Relative time position of major inflection point within the upcall

Mean value of frequency measurements from first 3 formants for each call

A normalized measure of the peakedness of the frequency distribution surrounding local maxima of the spectrum. A spectrum with pure tone harmonics will have a higher kurtosis than a signal with more energy between peaks of harmonics

A measure of asymmetry of the distribution of frequency values

Frequency at which first, second, and third quartiles of total energy in call occur

A measure of shape of the frequency distribution. Lower values indicate more tonal structure; higher values indicate a signal that more closely resembles white noise 


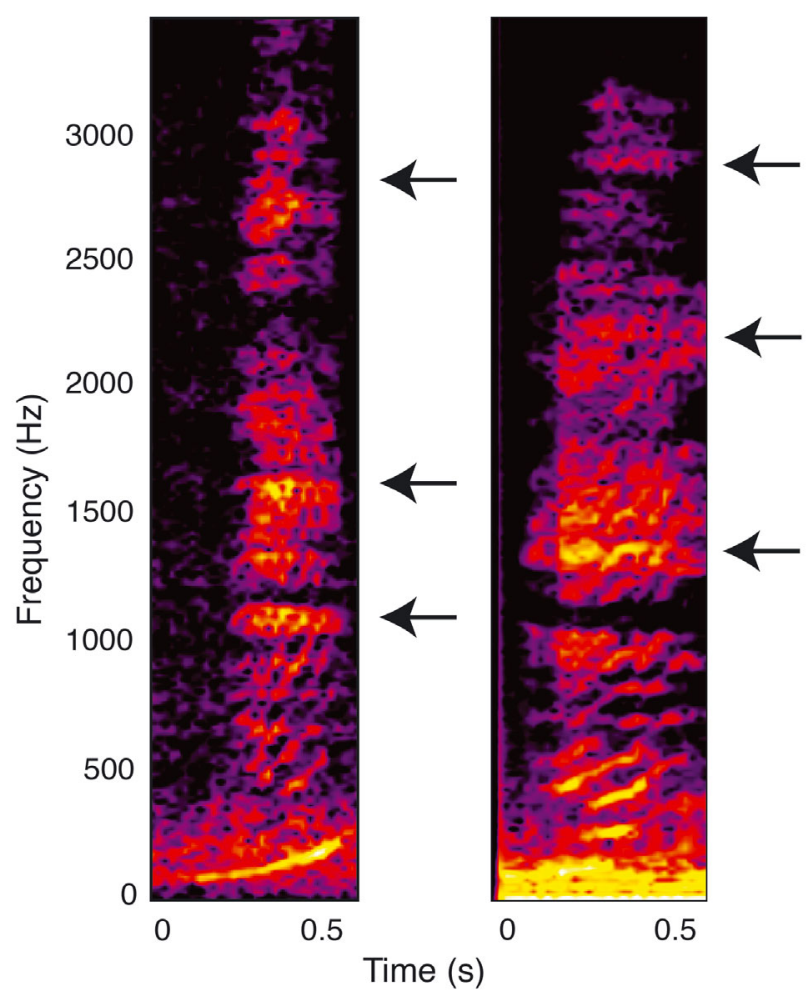

Fig. 1. Spectrograms of 2 North Atlantic right whale Eubalaena glacialis individuals, including higher frequency harmonics and formant structure visible as emphasized frequency bands, with arrows marking the lowest 3 formant frequencies for upcalls. Spectrograms were calculated using 1024 points, overlap of $50 \%$, and a Hann window resulting in frequency resolution of $15.6 \mathrm{~Hz}$ and temporal resolution of $32 \mathrm{~ms}$

ments in order to remove the effects of the noise (Table 1). Cepstral analysis can be used to separate the effects of source (vocal cords) and filter (vocal tract) by taking the Inverse Fourier Transform of the logarithm of the estimated spectrum of a signal, compressing the dynamic range, and reducing amplitude differences in the waveform (Reby et al. 2006). Since the method inverts the Fourier Transform, the independent variable of the cepstrum is known as the 'quefrency', a term that inverts 'frequency'; 'spectrogram' similarly becomes 'cepstrogram.' Contours were detected by determining the peak value in the cepstrum for each time step in a spectrogram, defined as the first peak after the initial decay that represents the initial sound source excitation followed by the decay of the vocal tract filter. Thus, the quefrency domain represents the combination of the sound source and vocal tract filter through addition rather than convolution, with lower values representing the vocal tract information; the sound source excitation (fundamental frequency) can be seen as a 'bump' at higher quefrencies. Cepstrograms were

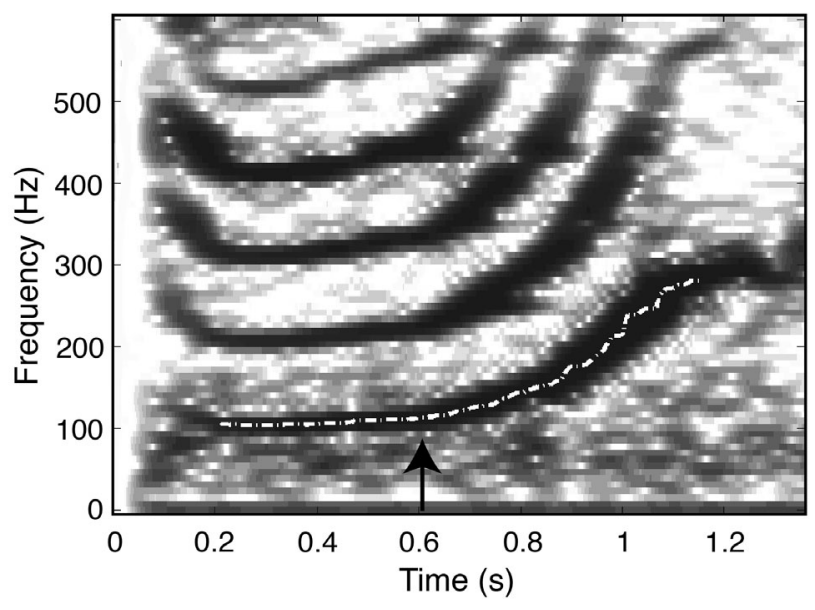

Fig. 2. North Atlantic right whale Eubalaena glacialis upcall showing detail of the fundamental frequency contour (white dashed line) and manually selected inflection point indicated with black arrow. Spectrograms were calculated using 1024 points, overlap of $50 \%$, and a Hann window resulting in frequency resolution of $15.6 \mathrm{~Hz}$ and temporal resolution of $32 \mathrm{~ms}$

calculated using 2048 points, 99\% overlap, and a Hann window. A longer window length with high overlap effectively smoothed the contour, limiting contour inflections and slopes to those most characteristic of the vocalization. The peak level of the cepstrogram at each time point was identified. The quefrency contour generated from the peak cepstral values was smoothed with a moving window average. Quefrency values were then converted to frequency. If necessary, the contours were manually adjusted to track the fundamental frequency. Spectrograms were calculated using 2048 points, overlap of $99 \%$, and a Hann window resulting in frequency resolution of $3.9 \mathrm{~Hz}$ and temporal resolution of $1.25 \mathrm{~ms}$. Analyses were limited to the middle 95\% energy of the full bandwidth of the recording. The inflection point, defined in this study as the beginning of the predominant rise in fundamental frequency, was selected manually using a graphical user interface (Fig. 2).

\section{Statistical analysis}

Preliminary assessment of measurement variables

Normality was visually assessed using Q-Q plots generated in SPSS v.22.0 (IBM). Normally distributed variables were entered into a multivariate analysis of variance (MANOVA) in R v.2.15.2 (R Development Core Team 2012) using age class or individual as the dependent variable. If the MANOVA was significant 


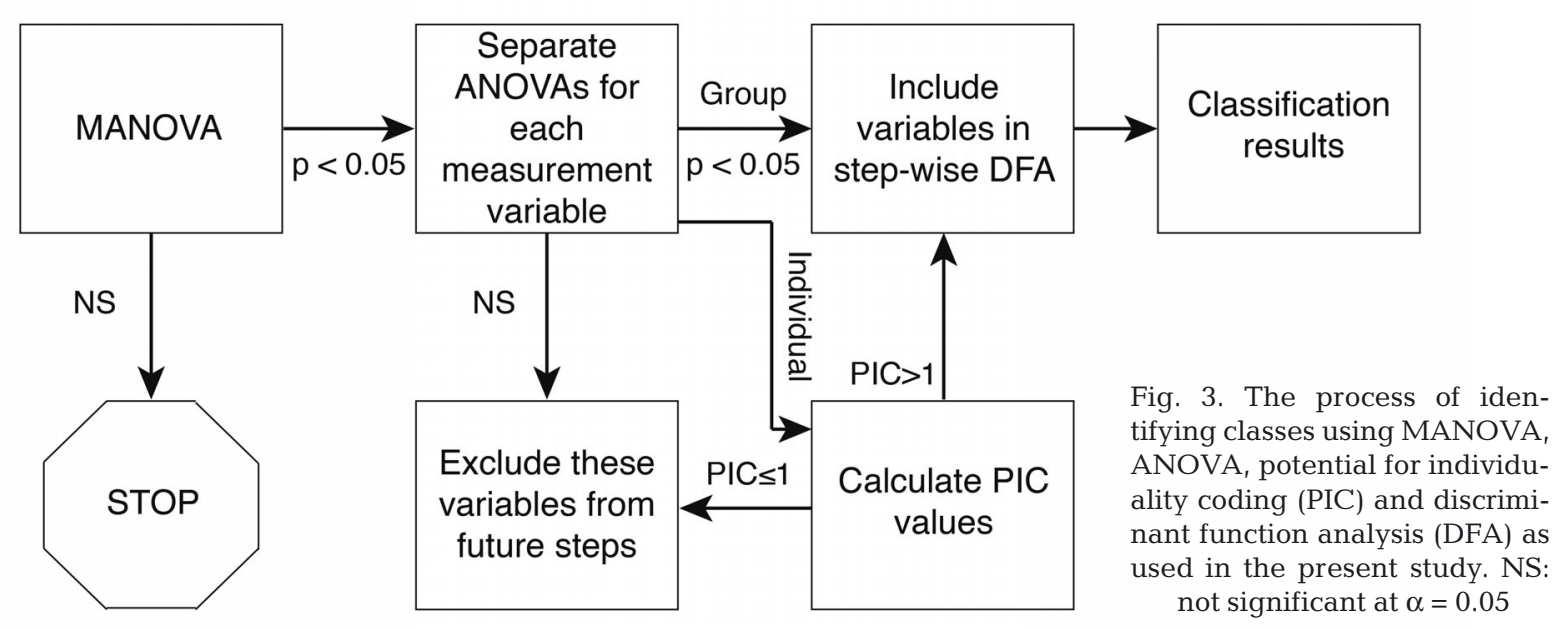

at $\alpha=0.05$, then separate analyses of variance (ANOVAs) with Bonferroni corrections were conducted to determine whether statistical differences existed among classes for specific measurement variables prior to further analyses (Fig. 3).

\section{Potential for individuality coding}

Each variable was assessed in terms of its potential for individuality coding (PIC) (Charrier et al. 2002). PIC values represent the ratio of the coefficient of variance for the entire dataset to the within-individual coefficient of variance. Thus, a PIC value $>1$ indicates that a particular variable exhibits greater inter-individual than intra-individual variation, making it a likely candidate for containing individually distinctive information (Charrier et al. 2002, Dreiss et al. 2014).

\section{Discriminant function analysis}

DFA assumptions are violated if all included variables are correlated with each other. We tested correlations among variables using principal components analysis (PCA). PCA confirmed that some variables were correlated with each other but none were correlated to all other variables. Therefore, since we were interested in determining the specific variables that were important in the discrimination process, we followed Blumstein \& Munos (2005) and included all measurement variables in the analysis. We performed stepwise DFA in SPSS (v.22.0; IBM) to classify calls to individual and age class. DFA classifies cases to groups based on the greatest separation of functions, with discriminant scores ranging from 0 to 1 . Stepwise DFA is a more conservative approach, as it only includes the variables that are most important to separating the groups and eliminates those that do not provide additional discriminatory information rather than using all possible variables simultaneously as in a full DFA (standard criteria used for this analysis: $F>3.84$ to enter, $F<2.71$ to remove).

Discriminant functions were determined to be significant $(p<0.05)$ according to a $\chi^{2}$ test with the null hypothesis that the discriminant function is equal to zero, or that addition of the function adds no further discriminating ability (e.g. Boughman 1997). Important variables were selected as variables included in the final stepwise DFA that also had a correlation value $\geq 0.5$ with a significant discriminant function.

Our sample size did not allow for separate training and testing sets; therefore, we used leave-one-out cross-validation to assess the strength of our classification results. In leave-one-out analysis, 1 case is removed from analysis, and discriminant functions are calculated based on the remaining cases. The withheld case is assigned to a group based on these functions; if the cross-validated classification results are based on group distinctiveness then the withheld cases will be correctly assigned to their parent groups at a greater-than-chance rate.

Due to the unequal number of calls represented by each individual and each demographic category, chance proportions for each analysis were calculated according to the following formula:

$$
\hat{c}=\frac{\sum_{i=1}^{k} p_{i} a_{i}}{N}
$$

where $k$ is the number of individual whales or demographic categories, $p$ is the proportion of the total number of calls $(N)$ represented by each whale or demographic category, and $a$ is the number of calls assigned to that individual or category.

Prior probabilities for the DFA were based on group size (no. of calls per individual or age class) in 
Table 2. Tag records of North Atlantic right whales Eubalaena glacialis used in the analysis. EGNO: catalog number in the North Atlantic Right Whale Catalog; BOF: Bay of Fundy; CCB: Cape Cod Bay; SEUS: Southeast United States

\begin{tabular}{|lcccccccc|}
\hline $\begin{array}{l}\text { Age } \\
\text { class }\end{array}$ & Sex & Habitat & EGNO & $\begin{array}{c}\text { Exact } \\
\text { age (yr) }\end{array}$ & $\begin{array}{c}\text { Minimum } \\
\text { age (yr) }\end{array}$ & $\begin{array}{c}\text { Tagging } \\
\text { date (mm/dd/yy) }\end{array}$ & $\begin{array}{c}\text { Focal } \\
\text { upcalls }\end{array}$ & $\begin{array}{c}\text { Duration of } \\
\text { recording (hh:mm:ss) }\end{array}$ \\
\hline Adult & Female & BOF & 2145 & 10 & - & $08 / 15 / 01$ & 20 & $04: 11: 37$ \\
Adult & Female & CCB & 1604 & Unknown & $>29$ & $04 / 26 / 15$ & 12 & $00: 40: 00$ \\
Adult & Female & CCB & 3101 & 9 & - & $04 / 05 / 10$ & 11 & $04: 02: 56$ \\
Adult & Female & BOF & 2413 & 11 & - & $08 / 03 / 05$ & 9 & $16: 26: 35$ \\
Adult & Female & BOF & 1241 & 23 & - & $08 / 01 / 05$ & 8 & $00: 20: 00$ \\
Adult & Female & CCB & 1703 & 28 & - & $04 / 30 / 15$ & 8 & $03: 53: 46$ \\
Adult & Female & SEUS & 2040 & 24 & - & $02 / 10 / 14$ & 4 & $05: 30: 00$ \\
Adult & Female & CCB & 1620 & Unknown & $>29$ & $04 / 25 / 15$ & 3 & $01: 04: 49$ \\
Adult & Male & BOF & 2350 & Unknown & $>11$ & $08 / 09 / 02$ & 93 & $07: 54: 00$ \\
Juvenile & Female & BOF & 3103 & 1 & - & $08 / 10 / 02$ & 10 & $01: 44: 00$ \\
Juvenile & Male & SEUS & 3442 & 2 & - & $01 / 21 / 06$ & 15 & $01: 21: 00$ \\
Juvenile & Male & CCB & 3579 & 4 & - & $04 / 17 / 09$ & 11 & $04: 02: 26$ \\
Juvenile & Male & BOF & 3323 & 2 & - & $07 / 29 / 05$ & 9 & $01: 54: 40$ \\
Unknown & Female & BOF & 3360 & Unknown & $>2$ & $08 / 14 / 05$ & 10 & $09: 00: 00$ \\
\hline
\end{tabular}

all analyses, thus allowing for the unbalanced group sizes. We used the exact binomial test in $\mathrm{R}$ to assess whether the percentage of correctly classified calls differed from chance for each of the DFA classification results.

The adult male whale demographic was represented by only a single individual with a large $N$ (93 calls), which could have influenced the results of the analysis for individuality. Therefore, we removed this individual from the analysis and re-ran the ANOVA and DFA in its absence using the same criteria as above for individual identification. As with the full dataset, classification results excluding this individual were then tested against chance values using the exact binomial test in $\mathrm{R}$.

\section{RESULTS}

A total of 14 whales had at least 3 upcalls that could confidently be assigned to that individual (median no. of upcalls ind. $.^{-1}=9$, range $=3$ to 93). One whale of unknown exact age (catalog \#3360) could not be definitively assigned to an age class based on its minimum age and was excluded from further analyses concerning age class (Table 2).

\section{Potential for variation}

Each overall MANOVA was significant $(p<0.001)$ whether using individual $(\mathrm{df}=13,198)$ or age $(\mathrm{df}=$ $1,200)$ as the dependent variable. For the separate ANOVAs, individual whales differed significantly in all measurement variables, while only certain variables resulted in significant differences between the 2 age classes. Almost all variables were significant at $p<0.05$. For age, the significant variables $(p<0.05)$ were inflection point, maximum fundamental frequency, end fundamental frequency, coefficient of variation of fundamental frequency, spectral entropy, duration, and formant 2 (Table 3).

\section{Potential for individuality coding}

All variables had a median PIC > 1 (range: 1.15 to 1.94) and were subsequently used as independent variables in the stepwise DFA for individual (see

Table 3. Results of separate ANOVAs for each variable for age class of North Atlantic right whales Eubalaena glacialis. Significant $p$-values are in bold; NS: not significant at $\alpha=0.05$

\begin{tabular}{|lc|}
\hline Measurement & Age \\
\hline Inflection point (\%) & $<\mathbf{0 . 0 1}$ \\
Mean fundamental frequency (Hz) & NS \\
Maximum fundamental frequency $(\mathrm{Hz})$ & $<\mathbf{0 . 0 5}$ \\
Minimum fundamental frequency $(\mathrm{Hz})$ & $\mathrm{NS}$ \\
Start fundamental frequency (Hz) & $\mathrm{NS}$ \\
End fundamental frequency (Hz) & $<\mathbf{0 . 0 5}$ \\
Coefficient of variation of fundamental & $<\mathbf{0 . 0 5}$ \\
frequency (Hz) & $\mathrm{NS}$ \\
Kurtosis of spectrum & $\mathrm{NS}$ \\
Skewness of spectrum & $<\mathbf{0 . 0 0 1}$ \\
Spectral entropy & $<\mathbf{0 . 0 0 1}$ \\
Duration 95\% (s) & $\mathrm{NS}$ \\
Formant 1 (Hz) & $<\mathbf{0 . 0 1}$ \\
Formant 2 (Hz) & $\mathrm{NS}$ \\
Formant 3 (Hz) & \\
\hline
\end{tabular}


Table S1 in the Supplement at www.int-res.com/ articles/suppl/n030p157_supp.pdf). A summary of all measurement variables by individual and age class can be found in Table S2 in the Supplement.

\section{Discriminant function analysis}

Stepwise DFA was able to correctly assign calls to individual and age class at levels significantly greater than chance (1-tailed binomial test using crossvalidated percentages, $\mathrm{p}<0.001$ for all analyses) (all individuals: Table 4; excluding adult male: Table S3 in the Supplement).

\section{Individuality}

For individual, a total of 7 discriminant functions were significant (Wilks' lambda, $\mathrm{p}<0.01$ for all functions) (Fig. 4). Important variables for individual discrimination, in decreasing order of canonical correlation coefficients were: mean fundamental frequency, start fundamental frequency, second formant, coefficient of variation of the fundamental frequency, spectral entropy, duration $95 \%$, skewness of the spectrum, and the percent time of the inflection point.

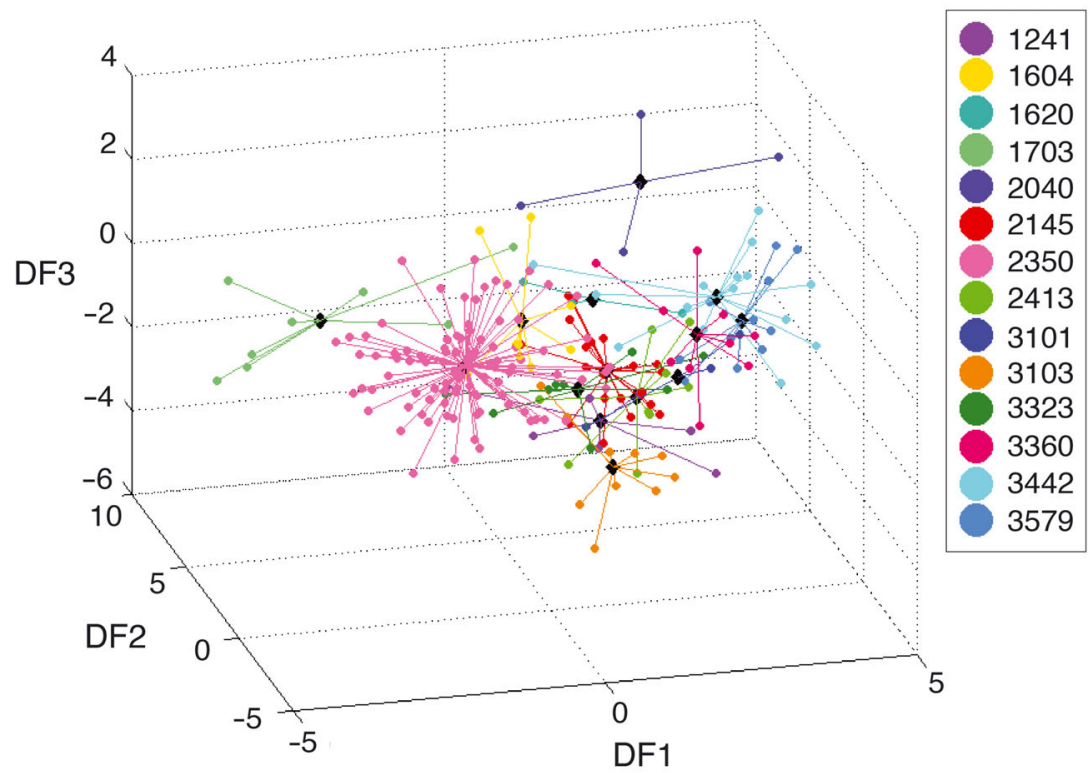

Fig. 4. Canonical discriminant scores for first 3 discriminant functions $(\mathrm{DF} 1=$ first discriminant function, DF2 $=$ second discriminant function, DF3 $=$ third discriminant function) used to differentiate among individual North Atlantic right whales Eubalaena glacialis. Correct classification after leave-one-out cross-validation based on a total of 7 discriminant functions was $72.6 \%$. Each point represents a single upcall; colors indicate individual whales, and lines are drawn from each call to the group centroid of canonical discriminant scores for that individual
Table 4. Classification results of discriminant function analysis for North Atlantic right whale Eubalaena glacialis individual and age class based on measurements of upcalls

\begin{tabular}{|lcrccc|}
\hline Grouping & $\begin{array}{c}\text { No. } \\
\text { of } \\
\text { whales }\end{array}$ & $\begin{array}{c}\text { No. } \\
\text { of } \\
\text { calls }\end{array}$ & $\begin{array}{c}\text { Adjusted } \\
\text { chance } \\
\text { classifi- } \\
\text { cation }\end{array}$ & $\begin{array}{c}\text { rectly } \\
\text { classi- } \\
\text { fied }\end{array}$ & $\begin{array}{c}\text { Cross- } \\
\text { validated } \\
\text { correctly } \\
\text { classified }\end{array}$ \\
\hline $\begin{array}{l}\text { Individual } \\
\text { Age }\end{array}$ & 14 & 212 & 22.25 & 76.9 & 72.6 \\
$\begin{array}{l}\text { Adult } \\
\text { Juveniles }\end{array}$ & 9 & 157 & & & \\
Total & 13 & 202 & 65.37 & 87.6 & 86.1 \\
\hline
\end{tabular}

Age class

For age class, one discriminant function was used to discriminate between the 2 groups (Fig. 5). The important variables for age discrimination were the spectral entropy and duration 95\% (see Fig. S1 in the Supplement).

\section{DISCUSSION}

The goal of this study was to investigate the potential for differentiating individual North Atlantic right whales based on measurements of a shared contact call type-the upcall. Using stepwise DFA, calls were classified to the correct individual and age class well above the level of classification expected by random chance. To our knowledge, this is the first quantitative assessment of acoustic variation among individuals using a stereotyped social call produced throughout the year by all individuals (Parks et al. 2011) and represents only the second such analysis of individuality in a stereotyped call of any mysticete whale (Hafner et al. 1979). As in studies of terrestrial mammals (Reby et al. 1998, Gamba et al. 2012), a combination of measurements from the fundamental frequency and the formants of the calls were effective for discrimination among individuals and groups. Our classification accuracies for individual identification of upcalls compared well with other mammals such as northern white rhinos Ceratotherium cottoni (N $=6$ rhinos, $74 \%$ cross-validated correct 


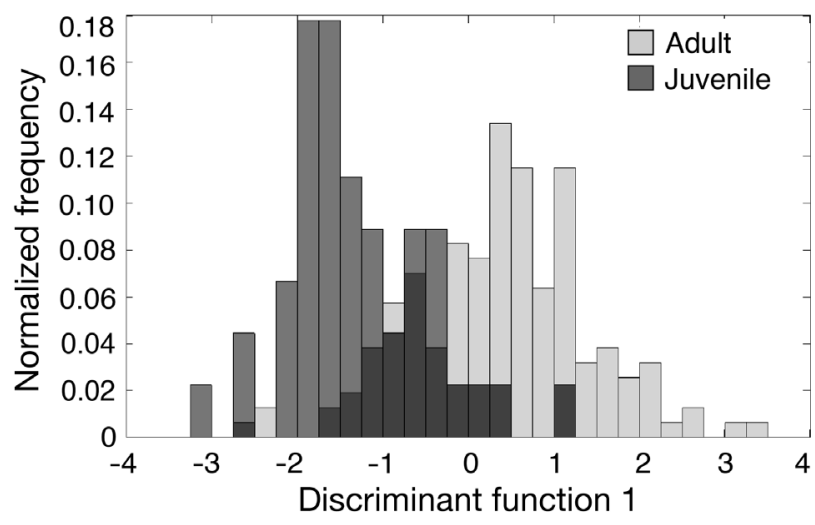

Fig. 5. Canonical discriminant scores for the discriminant function for age class of North Atlantic right whales Eubalaena glacialis. Correct classification after leave-one-out cross-validation was $86.1 \%$ for age class. The overlap between adult and juvenile discriminant functions is shown with shading of the histograms

DFA classification) (Cinková \& Policht 2014), giant otters Pteronura brasiliensis $\mathrm{N}=9,56.3 \%$ correctly classified calls) (Mumm et al. 2014) and bottlenose dolphins Tursiops truncatus $(\mathrm{N}=5,80 \%$ correctly classified calls) (McCowan \& Reiss 2001).

Spectral entropy was the most important variable for discriminating between age class, followed by duration. The higher value of spectral entropy in juveniles suggests that adult calls should be more tonal in nature, and that acoustic nonlinear phenomena (Tyson et al. 2007) may be more prevalent in calls of younger whales. Similarly, the importance of duration (with adults having longer calls than juveniles; Fig. 6), follows the results of Parks et al. (2011) for right whales as well as age-based differences in vocalizations of other species (Harnsberger et al. 2008, Sousa-Lima et al. 2008). Given major changes in body size that occur during maturation (Fortune et al. 2012), it is unclear whether these differences in signals are a result of body size differences, or physical maturation of the sound production mechanisms in this species.

This study shows that even the 'low frequency' calls of the North Atlantic right whale contain formant information up to $2.5 \mathrm{kHz}$, information that contributes to discrimination among individuals. Recording efforts, however, still suffer from technical limitations: especially with multiple simultaneous recorders, deployment time is limited by battery life and available data storage space. The tradeoffs of these practical considerations often result in recorders with sample rates that are only sufficient to record the fundamental frequency of a call of interest; for example, Mellinger et al. (2007a) and Bort et al. (2015) were limited to

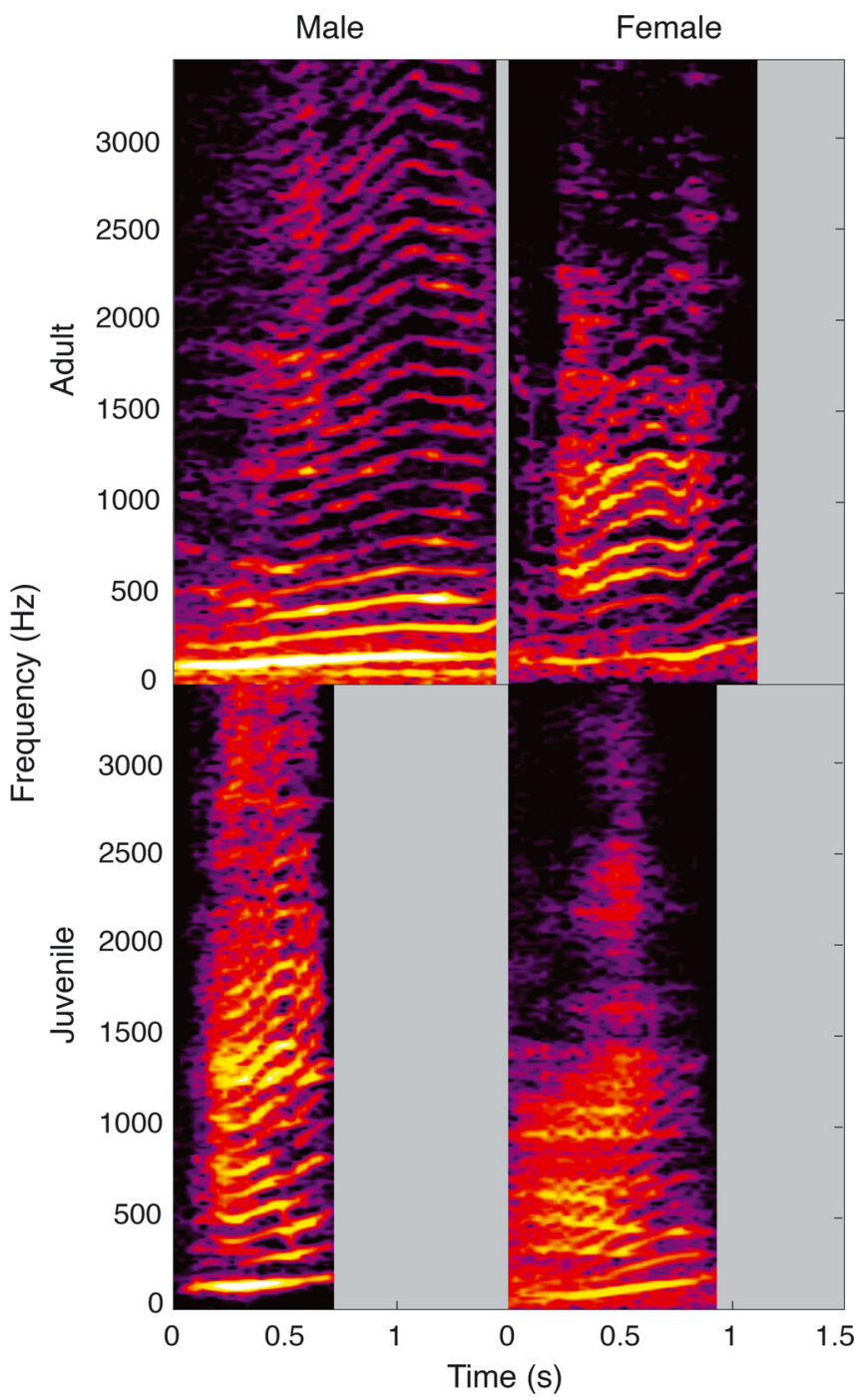

Fig. 6. Spectrograms highlighting the differences in upcalls between age classes of North Atlantic right whale Eubalaena glacialis, particularly emphasizing the shorter duration of juvenile whale upcalls (mean $\pm \mathrm{SD}$ : juveniles $=0.76 \pm 0.22 \mathrm{~s}$; adults $=1.09 \pm 0.29 \mathrm{~s}$ ). Male and female examples are included to indicate that this difference occurs regardless of sex

sample rates of $2 \mathrm{kHz}$ for right whale monitoring. When choosing sampling rates, researchers should consider that there may be additional discrimination possible if higher frequencies are included in autonomously recorded datasets. Future work should incorporate higher sample rates for autonomous recording of mysticetes, particularly as advances in technology allow for larger storage and longer battery life.

There are a number of challenges to address before the method of identifying individual right whales using passive acoustics can be fully developed. One of the limitations to this study was the lack of multiple recordings of the same individual separated by 
time and space. Without such separation, there is a risk that idiosyncratic attributes of a particular day or tagging event may have affected the calls of any given individual. Furthermore, the duration of any given recording may not have captured the full variability of the upcalls of an individual on a scale of hours or days. At longer time scales, knowing how whales change aspects of their identity signals as they move through different habitats over the course of a year, or if call parameters change over an individual's lifetime will also be necessary before incorporating vocal individuality within long-term monitoring efforts. Given the ability to discriminate between age classes in this study, changes in vocal parameters over an individual whale's lifetime are very likely and could be measured with repeated recordings of the same animal throughout its life.

Sex differences are found in many other mammal calls (Bachorowski \& Owren 1999, Blumstein \& Munos 2005, Charlton et al. 2009), and there may even be an interaction between body size and sex in the production of right whale upcalls. Only a single adult male was included in our analyses, therefore we could not assess calls for differences between the sexes. Additional data are clearly needed from males, particularly adults, to fully explore age and sex differences in the upcall. This would further enhance our understanding of call production in right whales and improve the information available from PAM surveys.

Our analysis was deliberately limited to calls obtained from tags physically placed on the focal animals, in order to confidently assign vocalizations to an individual for this proof-of-concept study. However, in the majority of PAM applications, right whale calls are recorded by hydrophones, where distance between the source whale and the recording unit varies (Mellinger et al. 2007a, Van Parijs et al. 2009, Matthews et al. 2014, Bort et al. 2015). This poses a challenge to analysis because as an upcall propagates through the environment, certain aspects of the call will degrade or become distorted due to transmission loss or multipath effects. For example, Munger et al. (2011) described propagation effects on the upcalls of North Pacific right whales in a shallow habitat $(\sim 70 \mathrm{~m})$, resulting in distinct arrivals of the call and corresponding multipath arrivals of timeand frequency-distorted versions of the call at distances $>20 \mathrm{~km}$. This likely has direct consequences for the use of any specific measurement as an identifying feature since acoustic characteristics of the received call-including multipath signals - will change over long distances.
Although suction cup tags are an excellent way to ensure the identity of a caller, they do not allow assessment of any propagation effects. Using a directional hydrophone or multiple recorders, it is possible to assign calls to individual whales using localization techniques and without using tags (e.g. Parks \& Tyack 2005). With such techniques, the propagation of specific acoustic features, especially those which are likely to encode individuality, could be measured if the same individual were recorded simultaneously using a tag and hydrophones at varying distances. In king penguins Aptenodytes patagonicus (Aubin et al. 2000) and black-capped chickadees Poecile atricapillus (Christie et al. 2004), the low-frequency call components most useful for measuring individuality were also the most robust to degradation from propagation through the environment. Regardless of the recognition capabilities of whales, propagation testing would be useful to determine how the distinctive features of the upcall propagate through the environment for purposes of monitoring this endangered species.

Based on the results of this study, we suggest that information is available within the upcall that can allow for statistical determination of individual identity and age class. This has the potential to enhance the information available through passive acoustic monitoring of this species. Future work should explore the stability of these signals over distance, increase the sample size to encompass repeat recordings and more individuals in each demographic group, and attempt to assess the usefulness of the information with respect to survey efforts.

Acknowledgements. The authors thank the numerous field teams and funding agencies that contributed to the collection of the dataset used in this study. Teams include those from the Woods Hole Oceanographic Institution, International Fund for Animal Welfare, North Atlantic Right Whale Consortium, New England Aquarium, Duke University, Syracuse University, Penn State University, and the National Oceanic and Atmospheric Administration (NOAA). Financial support for tagging studies was provided by the Office of Naval Research, US Fleet Forces Command and managed by Naval Facilities Engineering Command Atlantic as part of the US Navy's Marine Species Monitoring Program, NOAA National Marine Fisheries Service, Stellwagen Bank National Marine Sanctuary, Woods Hole Oceanographic Institution, Duke University, National Fish and Wildlife Foundation, International Fund for Animal Welfare, Massachusetts Division of Marine Fisheries, Massachusetts Environmental Trust, Cooperative Institute for Climate and Ocean Research, and the Cecil and Ida Green Technology Award. All data were collected under permits from the National Marine Fisheries Service and the Department of Fisheries and Oceans Canada. IACUC approval was ob- 
tained from the Woods Hole Oceanographic Institution, Cornell University, Syracuse University, and Duke University. We thank P. Tyack and M. Johnson for access to the 2001/ 2002 tag data and D. Nowacek, A. Nousek-McGregor, and A. Bocconcelli for access to the 2006 tag data. H. Blair, L. Matthews, and J. Thornton provided input throughout the project, and we are grateful to J. Friedman, S. Pitnick, M. Lomolino, and D. Quin for their insightful comments on previous drafts of the manuscript.

\section{LITERATURE CITED}

Antunes R, Schulz T, Gero S, Whitehead H, Gordon J, Rendell L (2011) Individually distinctive acoustic features in sperm whale codas. Anim Behav 81:723-730

$\mathrm{Au}$ WWL, Hastings MC (2010) Principles of marine bioacoustics. Springer, New York, NY

> Aubin T, Jouventin P, Hildebrand C (2000) Penguins use the two-voice system to recognize each other. Proc R Soc B 267:1081-1087

> Bachorowski JA, Owren MJ (1999) Acoustic correlates of talker sex and individual talker identity are present in a short vowel segment produced in running speech. J Acoust Soc Am 106:1054-1063

Bee MA, Kozich CE, Blackwell KJ, Gerhardt HC (2001) Individual variation in advertisement calls of territorial male green frogs, Rana clamitans: implications for individual discrimination. Ethology 107:65-84

Blumstein DT, Munos O (2005) Individual, age and sexspecific information is contained in yellow-bellied marmot alarm calls. Anim Behav 69:353-361

Blumstein DT, Mennill DJ, Clemins P, Girod L and others (2011) Acoustic monitoring in terrestrial environments using microphone arrays: applications, technological considerations and prospectus. J Appl Ecol 48:758-767

Boersma P, Weenink D (2012) Praat: doing phonetics by computer. Version 5.3.17. http://www.praat.org/ (accessed 15 October 2015)

Bort J, Van Parijs SM, Stevick PT, Summers E, Todd S (2015) North Atlantic right whale Eubalaena glacialis vocalization patterns in the central Gulf of Maine from October 2009 through October 2010. Endang Species Res 26: 271-280

Boughman JW (1997) Greater spear-nosed bats give groupdistinctive calls. Behav Ecol Sociobiol 40:61-70

Brown MW, Kraus SD, Gaskin DE, White BN (1994) Sexual composition and analysis of reproductive females in the North Atlantic right whale, Eubalaena glacialis, population. Mar Mamm Sci 10:253-265

Brown MW, Kraus SD, Slay CK, Garrison LP (2007) Surveying for discovery, science, and management. In: Kraus SD, Rolland RM (eds) The urban whale: North Atlantic right whales at the crossroads. Harvard University Press, Cambridge, MA, p 105-137

> Burgess WC (2009) The Acousonde: a miniature autonomous wideband recorder. J Acoust Soc Am 125:2588

> Caldwell MC, Caldwell DK (1965) Individualized whistle contours in bottle-nosed dolphins (Tursiops truncatus). Nature 207:434-435

> Caswell H, Fujiwara M, Brault S (1999) Declining survival probability threatens the North Atlantic right whale. Proc Natl Acad Sci USA 96:3308-3313

- Cazau D, Adam O, Laitman JT, Reidenberg JS (2013) Understanding the intentional acoustic behavior of humpback whales: a production-based approach. J Acoust Soc Am 134:2268-2273

Charlton BD, Zhihe Z, Snyder RJ (2009) The information content of giant panda, Ailuropoda melanoleuca, bleats: acoustic cues to sex, age and size. Anim Behav 78: 893-898

Charrier I, Harcourt RG (2006) Individual vocal identity in mother and pup Australian sea lions (Neophoca cinerea). J Mammal 87:929-938

> Charrier I, Mathevon N, Jouventin P (2002) How does a fur seal mother recognize the voice of her pup? An experimental study of Arctocephalus tropicalis. J Exp Biol 205: 603-612

> Charrier I, Pitcher BJ, Harcourt RG (2009) Vocal recognition of mothers by Australian sea lion pups: individual signature and environmental constraints. Anim Behav 78: 1127-1134

> Christie PJ, Mennill DJ, Ratcliffe LM (2004) Chickadee song structure is individually distinctive over long broadcast distances. Behaviour 141:101-124

Cinková I, Policht R (2014) Contact calls of the northern and southern white rhinoceros allow for individual and species identification. PLoS ONE 9:e98475

Clark CW (1982) The acoustic repertoire of the southern right whale, a quantitative analysis. Anim Behav 30: 1060-1071

> Clemins PJ, Johnson MT, Leong KM, Savage A (2005) Automatic classification and speaker identification of African elephant (Loxodonta africana) vocalizations. J Acoust Soc Am 117:956-963

> Dawson DK, Efford MG (2009) Bird population density estimated from acoustic signals. J Appl Ecol 46:1201-1209

> Dreiss AN, Ruppli CA, Roulin A (2014) Individual vocal signatures in barn owl nestlings: Does individual recognition have an adaptive role in sibling vocal competition? J Evol Biol 27:63-75

Fortune SM, Trites AW, Perryman WL, Moore MJ, Pettis HM, Lynn MS (2012) Growth and rapid early development of North Atlantic right whales (Eubalaena glacialis). J Mammal 93:1342-1354

Gamba M, Colombo C, Giacoma C (2012) Acoustic cues to caller identity in lemurs: a case study. J Ethol 30:191-196

> Gillam EH, Chaverri G (2012) Strong individual signatures and weaker group signatures in contact calls of Spix's disc-winged bat, Thyroptera tricolor. Anim Behav 83: 269-276

Gwilliam J, Charrier I, Harcourt RG (2008) Vocal identity and species recognition in male Australian sea lions Neophoca cinerea. J Exp Biol 211:2288-2295

> Hafner GW, Hamilton CL, Steiner WW, Thompson TJ, Winn HE (1979) Signature information in the song of the humpback whale. J Acoust Soc Am 66:1-6

Hamilton PK, Martin SM (1999) A catalog of identified right whales from the western North Atlantic: 1935-1997. New England Aquarium, Boston, MA

> Harnsberger JD, Shrivastav R, Brown WS Jr, Rothman H, Hollien $H$ (2008) Speaking rate and fundamental frequency as speech cues to perceived age. J Voice 22:58-69

Insley SJ, Phillips AV, Charrier I (2003) A review of social recognition in pinnipeds. Aquat Mamm 29:181-201

Janik VM, Sayigh LS (2013) Communication in bottlenose dolphins: 50 years of signature whistle research. J Comp Physiol A Neuroethol Sens Neural Behav Physiol 199: 479-489

Johnson MP, Tyack PL (2003) A digital acoustic recording 
tag for measuring the response of wild marine mammals to sound. IEEE J Oceanic Eng 28:3-12

Kinnunen T, Li H (2010) An overview of text-independent speaker recognition: from features to supervectors. Speech Commun 52:12-40

Kraus SD, Hatch JJ (2001) Mating strategies in the North Atlantic right whale (Eubalaena glacialis). J Cetacean Res Manag 2:237-244

Kraus SD, Rolland RM (2007) Right whales in the urban ocean. In: Kraus SD, Rolland RM (eds) The urban whale: North Atlantic right whales at the crossroads. Harvard University Press, Cambridge, MA, p 1-38

Kraus SD, Moore KE, Price CA, Crone MJ, Watkins WA, Winn HE, Prescott JH (1986) The use of photographs to identify individual North Atlantic right whales (Eubalaena glacialis). Rep Int Whaling Comm 10(Spec Issue): 145-151

Kraus SD, Brown MW, Caswell H, Clark CW and others (2005) North Atlantic right whales in crisis. Science 309: 561-562

Kremers D, Lemasson A, Almunia J, Wanker R (2012) Vocal sharing and individual acoustic distinctiveness within a group of captive orcas (Orcinus orca). J Comp Psychol 126:433-445

Küsel ET, Mellinger DK, Thomas L, Marques TA, Moretti D, Ward J (2011) Cetacean population density estimation from single fixed sensors using passive acoustics. J Acoust Soc Am 129:3610-3622

Makhoul J (1975) Linear prediction: a tutorial review. Proc IEEE 63:561-580

> Marques TA, Munger L, Thomas L, Wiggins S, Hildebrand JA (2011) Estimating North Pacific right whale Eubalaena japonica density using passive acoustic cue counting. Endang Species Res 13:163-172

Marques TA, Thomas L, Martin SW, Mellinger DK and others (2013) Estimating animal population density using passive acoustics. Biol Rev Camb Philos Soc 88:287-309

Matthews JN, Brown S, Gillespie D, Johnson M and others (2001) Vocalisation rates of the North Atlantic right whale (Eubalaena glacialis). J Cetacean Res Manag 3: 271-282

Matthews LP, McCordic JA, Parks SE (2014) Remote acoustic monitoring of North Atlantic right whales (Eubalaena glacialis) reveals seasonal and diel variations in acoustic behavior. PLoS ONE 9:e91367

> McCowan B, Reiss D (2001) The fallacy of 'signature whistles' in bottlenose dolphins: a comparative perspective of 'signature information' in animal vocalizations. Anim Behav 62:1151-1162

Mellinger DK, Nieukirk SL, Matsumoto H, Heimlich SL and others (2007a) Seasonal occurrence of North Atlantic right whale (Eubalaena glacialis) vocalizations at two sites on the Scotian Shelf. Mar Mamm Sci 23:856-867

Mellinger DK, Stafford KM, Moore SE, Dziak RP, Matsumoto H (2007b) An overview of fixed passive acoustic observation methods for cetaceans. Oceanography 20: 36-45

> Mercado E III, Schneider JN, Pack AA, Herman LM (2010) Sound production by singing humpback whales. J Acoust Soc Am 127:2678-2691

> Morano JL, Rice AN, Tielens JT, Estabrook BJ, Murray A, Roberts BL, Clark CW (2012) Acoustically detected yearround presence of right whales in an urbanized migration corridor. Conserv Biol 26:698-707

Mumm CAS, Urrutia MC, Knörnschild M (2014) Vocal indi- viduality in cohesion calls of giant otters, Pteronura brasiliensis. Anim Behav 88:243-252

- Munger LM, Wiggins SM, Hildebrand JA (2011) North Pacific right whale up-call source levels and propagation distance on the southeastern Bering Sea shelf. J Acoust Soc Am 129:4047-4054

Nichols N, Atlas L, Bowles A, Roch MA (2010) Call and component evaluation for improved performance of recognition of killer whale individuals. In: Proc IEEE OCEANS 2010 Conf, 20-23 Sep 2010, Seattle, WA

Nousek AE, Slater PJB, Wang C, Miller PJO (2006) The influence of social affiliation on individual vocal signatures of northern resident killer whales (Orcinus orca). Biol Lett 2:481-484

Nousek-McGregor AE (2010) The cost of locomotion in North Atlantic right whales Eubalaena glacialis. PhD dissertation, Duke University, Durham, NC

Nowacek DP, Johnson MP, Tyack PL, Shorter KA, McLellan WA, Pabst DA (2001) Buoyant balaenids: the ups and downs of buoyancy in right whales. Proc R Soc B 268: 1811-1816

> Nowacek DP, Johnson MP, Tyack PL (2004) North Atlantic right whales (Eubalaena glacialis) ignore ships but respond to alerting stimuli. Proc R Soc B 271:227-231

Parks SE, Clark CW (2007) Acoustic communication: social sounds and the potential impacts of noise. In: Kraus SD, Rolland RM (eds) The urban whale: North Atlantic right whales at the crossroads. Harvard University Press, Cambridge, MA, p 310-332

$>$ Parks SE, Tyack PL (2005) Sound production by North Atlantic right whales (Eubalaena glacialis) in surface active groups. J Acoust Soc Am 117:3297-3306

$>$ Parks SE, Searby A, Célérier A, Johnson MP, Nowacek DP, Tyack PL (2011) Sound production behavior of individual North Atlantic right whales: implications for passive acoustic monitoring. Endang Species Res 15:63-76

Payne R, Dorsey EM (1983) Sexual dimorphism and aggressive use of callosities in right whales (Eubalaena australis). In: Payne R (ed) Communication and behaviour of whales. AAAS Selected Symposium 76, Westview Press, Boulder, CO, p 295-329

Peake TM, McGregor PK (2001) Corncrake Crex crex census estimates: a conservation application of vocal individuality. Anim Biodivers Conserv 24:81-90

R Core Team (2012). R: a language and environment for statistical computing. R Foundation for Statistical Computing, Vienna. http://www.R-project.org/

$>$ Reby D, Joachim J, Lauga J, Lek S, Aulagnier S (1998) Individuality in the groans of fallow deer (Dama dama) bucks. J Zool (Lond) 245:79-84

> Reby D, McComb K, Cargnelutti B, Darwin C, Fitch WT, Clutton-Brock T (2005) Red deer stags use formants as assessment cues during intrasexual agonistic interactions. Proc R Soc B 272:941-947

- Reby D, Andre-Obrecht R, Galinier A, Farinas J (2006) Cepstral coefficients and hidden Markov models reveal idiosyncratic voice characteristics in red deer (Cervus elaphus) stags. J Acoust Soc Am 120:4080-4089

Reidenberg JS, Laitman JT (2007) Discovery of a low frequency sound source in mysticeti (baleen whales): anatomical establishment of a vocal fold homolog. Anat Rec (Hoboken) 290:745-759

$>$ Rendall D, Kollias S, Ney C, Lloyd P (2005) Pitch $\left(F_{0}\right)$ and formant profiles of human vowels and vowel-like baboon grunts: the role of vocalizer body size and voice-acoustic 
allometry. J Acoust Soc Am 117:944-955

Right Whale Consortium (2015) North Atlantic Right Whale Consortium identification database, 08/13/2015. New England Aquarium, Boston, MA

Sayigh LS, Esch HC, Wells RS, Janik VM (2007) Facts about signature whistles of bottlenose dolphins, Tursiops truncatus. Anim Behav 74:1631-1642

Sousa-Lima RS, Paglia AP, da Fonseca GAB (2008) Gender, age, and identity in the isolation calls of Antillean manatees (Trichechus manatus manatus). Aquat Mamm 34: 109-122

Sousa-Lima RS, Norris TF, Oswald JN, Fernandes DP (2013) A review and inventory of fixed autonomous recorders for passive acoustic monitoring of marine mammals. Aquat Mamm 39:23-53

Stanistreet JE, Risch D, Van Parijs SM (2013) Passive acoustic tracking of singing humpback whales (Megaptera novaeangliae) on a northwest Atlantic feeding ground. PLoS One 8:e61263

Taylor AM, Reby D (2010) The contribution of source-filter theory to mammal vocal communication research. J Zool (Lond) 280:221-236

Terry AMR, McGregor PK (2002) Census and monitoring based on individually identifiable vocalizations: the role of neural networks. Anim Conserv 5:103-111

Terry AMR, Peake TM, McGregor PK (2005) The role of

Editorial responsibility: Sascha Hooker, St. Andrews, UK vocal individuality in conservation. Front Zool 2:art10, doi:10.1186/1742-9994-2-10

Tibbetts EA, Dale J (2007) Individual recognition: it is good to be different. Trends Ecol Evol 22:529-537

Titze IR (2000) Principles of voice production, $2^{\text {nd }}$ edn. National Center for Voice and Speech, Iowa City, IA

> Tyson RB, Nowacek DP, Miller PJO (2007) Nonlinear phenomena in the vocalizations of North Atlantic right whales (Eubalaena glacialis) and killer whales (Orcinus orca). J Acoust Soc Am 122:1365-1373

Van Opzeeland IC, Van Parijs SM, Frickenhaus S, Kreiss CM, Boebel O (2012) Individual variation in pup vocalizations and absence of behavioral signs of maternal vocal recognition in Weddell seals (Leptonychotes weddellii). Mar Mamm Sci 28:E158-E172

Van Parijs SM, Clark CW, Sousa-Lima RS, Parks SE, Rankin S, Risch D, Van Opzeeland IC (2009) Management and research applications of real-time and archival passive acoustic sensors over varying temporal and spatial scales. Mar Ecol Prog Ser 395:21-36

Vannoni E, McElligott AG (2007) Individual acoustic variation in fallow deer (Dama dama) common and harsh groans: a source-filter theory perspective. Ethology 113: 223-234

Zimmer WMX (2011) Passive acoustic monitoring of cetaceans. Cambridge University Press, New York, NY

Submitted: August 19, 2015; Accepted: April 1, 2016

Proofs received from author(s): May 18, 2016 